\title{
Formação de Professores e os Sentidos Construídos para Tecnologias da Informação e Comunicação
}

\section{Teacher Formation and the Meanings Built for Information and Communication Technologies}

\author{
Adriana Maria de Souza Silva ${ }^{1}$, Adriane Corrêa da Silva ${ }^{1}$, Aline Andréia Nicolli*1
}

\begin{abstract}
RESUMO
O processo de construção de sentidos sobre Tecnologias da Informação e da Comunicação (TIC) a partir da análise dos Projetos Pedagógicos Curriculares (PPCs) de cinco Cursos de Licenciatura, da Universidade Federal do Acre (Ufac) e as implicações para a formação de novos professores, é o foco deste estudo. Para isso, delineamos como problema de pesquisa o que segue: Quais sentidos podem ser construídos para a expressão "Tecnologia da Informação e da Comunicação" quando da análise dos PPCs de Cursos de Licenciatura e suas implicações para a formação de professores? O estudo foi fundamentado nos pressupostos teóricos metodológicos da Análise de Discurso de Pêcheux $(1975,2006)$ e Orlandi $(2003$, 2009). O corpus de análise foi organizado a partir da leitura e análise minuciosa do texto dos PPCs e da identificação dos termos de busca relacionados as TICs. Os sentidos predominantes se materializaram, nos textos dos PPCs, como: i) ferramentas e dispositivos tecnológicos digitais; especificamente computadores e celulares; ii) sinônimo de evolução; iii) responsável por benefícios e iv) facilitadores da vida das pessoas.
\end{abstract}

Palavras-chave: Formação de professores; Tecnologias da informação e da comunicação; Projetos pedagógicos de licenciatura; Análise de discurso.

\section{ABSTRACT}

The process of constructing meanings on Information and Communication Technologies (ICT) from the analysis of pedagogical curricular projects (PPCs) of five Undergraduate Courses, from the Federal University of Acre (Ufac) and the implications for the formation of new teachers, it is the focus of this study. For this, we outline as a research problem the following: What meanings can be constructed for the expression "Information and Communication Technology" when analyzing the PPCs of Undergraduate Courses and their implications for teacher education? The study was based on the methodological theoretical assumptions of the Discourse Analysis of Pêcheux $(1975,2006)$ and Orlandi $(2003,2009)$. The corpus of analysis was organized from the reading and thorough analysis of the text of the PPCs and the identification of search terms related to ICTs. The predominant meanings materialized, in the texts of the PPCs, such as: i) digital tools and technological devices; specifically computers and mobile phones; ii) synonymous with evolution; iii) responsible for benefits and iv) facilitators of people's lives.

Keywords: Teacher formation; Information and communication technologies; Undergraduate pedagogical projects; Discourse analysis.

\footnotetext{
${ }^{1}$ Universidade Federal do Acre.

*E-mail: aanicolli@gmail.com
} 


\section{INTRODUÇÃO}

O interesse em investigar a Formação de Professores e os sentidos construídos para a expressão Tecnologias da Informação e da Comunicação (TICs) surgiu de inquietações e reflexões que realizamos, acerca do papel da Universidade frente ao desafio em atuar na formação inicial de professores, mediada pelas tecnologias neste tempo contemporâneo.

Para isso, tínhamos como pressuposto a possibilidade das TICs possibilitarem a formação de profissionais aptos a desenvolver habilidades e práticas críticas, voltadas para o uso dessas tecnologias, como uma ferramenta que promove a melhoria dos processos de ensino e de aprendizagem e nos propusemos a responder a seguinte questão: Quais sentidos podem ser construídos para a expressão "Tecnologia da Informação e da Comunicação" quando da análise dos Projetos Pedagógicos Curriculares dos Cursos de Licenciatura, de áreas distintas, nos diferentes Centros Acadêmicos, existentes na Ufac, Campus Rio Branco, e quais as implicações para a formação de professores?

Para tanto, o corpus empírico foi construído a partir da análise dos Projetos Pedagógicos Curriculares de 5 (cinco) cursos de Graduação em Licenciatura da Universidade Federal do Acre, Campus Rio Branco, que representam cada um dos Centros Acadêmicos que ofertam Cursos de Graduação em Licenciatura em aéreas distintas, organizados por afinidades, quais sejam: Centro de Educação Letras e Artes (CELA) - Curso de Pedagogia, Centro de Ciência Biológicas e da Natureza (CCBN) - Curso de Ciências Biológicas, Centro de Ciências da Saúde e Desporto (CCSD) Curso de Educação Física, Centro de Filosofia e Ciências Humanas (CFCH) - Curso de Geografia, Centro de Ciências Exatas e Tecnológicas (CCET) - Curso de Matemática.

Cabe destacar que tivemos como pressuposto teórico-metodológico a Análise de Discurso, de linha francesa de Michel Pêcheux (1975, 2006), e Eni Puccilnelli Orlandi (2003, 2009). A escolha pela Análise de Discurso de linha francesa se deu por considerarmos que "o que temos, em termos de real do discurso, é a descontinuidade, a dispersão, a incompletude, a falta, o equívoco, a contradição, constitutivas tanto do sujeito como do sentido" (ORLANDI, 2003, p.74)

Nessa perspectiva, trabalharemos o texto, não como produto, mas como processo discursivo que pressupõe condições concretas de produção, diferentes posições de sujeitos e várias formações discursivas. Nesse sentido, reforçamos que analisamos os Projetos Pedagógicos de cinco Cursos de Licenciatura, da Ufac, objetivando identificar a construção de sentidos à expressão - Tecnologias da Informação e da Comunicação - com intuito de compreendermos suas implicações no processo de formação de professores. Para tanto, consideraremos que "o discurso é o lugar em que se pode observar essa relação entre língua e ideologia, compreendendo-se como a língua produz sentidos por/para os sujeitos" (PÊCHEUX, 1975, p. 10). E acrescenta que,

Todo enunciado é intrinsecamente suscetível de tornar-se outro, diferente de si mesmo, se deslocar discursivamente de seu sentido para derivar para um outro. [...] todo enunciado, toda sequência de enunciados é, pois, linguisticamente descritível como uma série (léxico-sintaticamente determinada) de pontos de 
deriva possíveis, oferecendo lugar a interpretação. É nesse espaço que pretende trabalhar a análise de discurso (PÊCHEUX, 2006, p. 53).

Além disso, também, nos fundamentamos na afirmação de Orlandi (2002), a qual defende que todo discurso estabelece relação com outros, formando uma intricada discursividade, a ponto de um único texto refletir a presença de várias formações, que contraditoriamente, nele se organizam, tendo em vista uma formação dominante.

\section{ASPECTOS EDUCACIONAIS LEGAIS SOBRE AS TECNOLOGIAS DA INFORMAÇÃO E DA COMUNICAÇÃO}

Em contexto educacional, a Lei de Diretrizes e Bases da Educação Nacional (LDB), $\mathrm{n}^{\circ}$ 9.394/96, apresenta-se como um marco muito significativo na educação brasileira. A promulgação desta lei, demarcou um grande avanço nas questões educacionais do país, principalmente por trazer questões relacionadas ao uso das Tecnologias da Informação e da Comunicação como possíveis de serem incorporadas ao ensino superior e, consequentemente, à formação de docentes, haja vista, sua frequente utilização nos tempos contemporâneos.

Dessa forma, destacamos que o artigo 35, da referida Lei, elenca as finalidades do ensino médio, ressaltando a necessidade da compreensão dos fundamentos científico-tecnológicos dos processos produtivos e define as áreas do conhecimento a serem contempladas no ensino médio, quais sejam: linguagens e suas tecnologias; matemática e suas tecnologias; ciências da natureza e suas tecnologias.

III - incentivar o trabalho de pesquisa e investigação científica, visando o desenvolvimento da ciência e da tecnologia e da criação e difusão da cultura [...]; VII - promover a extensão, [...], visando à difusão [...]da pesquisa científica e tecnológica geradas na instituição; $\S 2$ o A formação continuada e a capacitação dos profissionais de magistério poderão utilizar recursos e tecnologias de educação a distância; § 3- A formação inicial de profissionais de magistério dará preferência ao ensino presencial, subsidiariamente fazendo uso de recursos e tecnologias de educação a distância (BRASIL, 1996, p. 21).

Neste sentido, percebemos o forte apelo, em relação a utilização das TICs na educação básica e consequentemente, na formação de professores, a partir de uma demanda do mercado capitalista. E ainda, nos artigos 61 e 62 - A, apresenta dispositivos acerca da formação de professores,

$\S 2^{\circ}$ A formação continuada e a capacitação dos profissionais de magistério poderão utilizar recursos e tecnologias de educação a distância; § $3^{\circ}-\mathrm{A}$ formação inicial de profissionais de magistério dará preferência ao ensino presencial, subsidiariamente fazendo uso de recursos e tecnologias de educação a distância; Art. 62-A. A formação dos profissionais a que se refere o inciso III do art. 61 far-se-á por meio de cursos de conteúdo técnicopedagógico, em nível médio ou superior, incluindo habilitações tecnológicas (BRASIL, 1996, p. 30). 
Mais uma evidência de que os marcos legais estão operando na direção da construção de um sujeito empreendedor de si mesmo, onde a educação está a serviço do mercado capitalista (LAZZARATO, 2017).

O atual Plano Nacional de Educação (PNE), aprovado em 25 de junho de 2014, por sua vez, apresenta as metas 12, 13 e 14 que indicam a necessidade de priorizar a promoção humanística, científica e tecnológica do país, a educação superior e, sobretudo, a formação docente. $\mathrm{O}$ item 3.11, da meta 3, por sua vez, traz a determinação de ampliação do acesso à rede mundial de computadores, para que a universalização do ensino seja possível.

Do mesmo modo, a Meta 4 prevê a inclusão de tecnologia assistiva para alunos com deficiência e de tecnologias educacionais para alfabetização. Enquanto a Meta 7 indica que as tecnologias são relevantes para aumentar o rendimento dos alunos e prevê como estratégias prover equipamentos e recursos tecnológicos digitais para a utilização pedagógica nas escolas de ensino fundamental e médio (BRASIL, 2014, p. 9).

Nas metas 8 e 9 encontramos a ênfase sobre a elevação da qualidade e o aumento de índices de desempenho, além da diminuição de desigualdades entre subgrupos de brasileiros, a saber:

8.1) institucionalizar programas e desenvolver tecnologias para correção de fluxo [...] ; 9.11) implementar programas de capacitação tecnológica da população jovem e adulta, direcionados para os segmentos com baixos níveis de escolarização formal e para os (as) alunos (as) com deficiência, articulando os sistemas de ensino, a Rede Federal de Educação Profissional, Científica e Tecnológica, as universidades, as cooperativas e as associações, por meio de ações de extensão, desenvolvidas em centros vocacionais tecnológicos, com tecnologias assistivas, que favoreçam a efetiva inclusão social e produtiva dessa população; 9.12) considerar [...] as necessidades dos idosos, com vistas $[\ldots]$ ao acesso a tecnologias educacionais [...] (BRASIL, 2014, p. 9).

As Metas 11 e 14 tratam da formação a distância como um caminho possível, e coloca as tecnologias como possibilidade de solução para os problemas de acesso à formação por meio da EaD (BRASIL, 2014). Por fim, encontramos na meta 15, a previsão de reforma curricular dos cursos de licenciatura e a renovação pedagógica, como alternativas para melhorar o aprendizado dos alunos,

15.6) promover a reforma curricular dos cursos de licenciatura e estimular a renovação pedagógica, de forma a assegurar o foco no aprendizado do (a) aluno (a), dividindo a carga horária em formação geral, formação na área do saber e didática específica e incorporando as modernas tecnologias de informação e comunicação, em articulação com a base nacional comum dos currículos da educação básica, de que tratam as estratégias 2.1, 2.2, 3.2 e 3.3 deste PNE (BRASIL, 2014, p. 12).

Além da LDB e do PNE analisamos os textos das Diretrizes Curriculares Nacionais dos Cursos de Licenciaturas, que são objetos desse estudo e percebemos que, de uma forma ou outra, todos fazem referência à utilização das Tecnologias de Informação e da Comunicação. 
Os textos da DCN ${ }^{2}$ de Pedagogia (2006) e Geografia (2002) enfatizam a formação de profissionais que façam uso de Tecnologias da Informação e da Comunicação. Tal perspectiva encontra-se na introdução, no perfil dos formandos e nas competências e habilidades. A DCN de Ciências Biológicas (2002), por sua vez, cita o uso das tecnologias de forma simplificada, não se preocupando com as competências que o profissional precisa desenvolver no uso dessas tecnologias. A DCN de Educação Física (2004), por sua vez, não faz menção ao termo Tecnologias da Informação e da Comunicação.

Na DCN do Curso de Matemática (2003), por sua vez, o termo tecnologia aparece no rol de competências e habilidades. Diz ainda que,

\begin{abstract}
Desde o início do curso e licenciando deve adquirir familiaridade com o uso do computador como instrumento de trabalho, incentivando-se sua utilização para o ensino de matemática, em especial para a formulação e solução de problemas. É importante também a familiarização do licenciando, ao longo do curso, com outras tecnologias que possam contribuir para o ensino de Matemática (BRASIL, 2001, p. 5).
\end{abstract}

Ao analisarmos as Diretrizes Curriculares foi possível perceber que, de um modo geral, elas trazem algum tipo de referência às Tecnologias da Informação e da Comunicação, ou apenas às Tecnologias. No entanto, não se preocupam em estabelecer critérios que poderiam efetivamente possibilitar a formação de profissionais aptos a desenvolver habilidades e práticas críticas, voltadas para o uso dessas tecnologias, como uma ferramenta que promove a melhoria dos processos de ensino e de aprendizagem.

Nota-se que, de forma geral, a preocupação em relação à inserção das TICs se dá pelo avanço do conhecimento e da tecnologia nas diferentes áreas, bem como no entendimento de que os recursos das Tecnologias da Informação e da Comunicação devem ser utilizados de forma a ampliar e diversificar as formas de interagir com as fontes de produção e conhecimentos específicos de cada área, com o propósito de promover contínua atualização e aperfeiçoamento profissional, visando uma maior qualidade no ensino e na aprendizagem de cada sujeito envolvido nesse processo.

Sobre essa realidade, Zuin (2010, p. 968) nos chama a refletir sobre a finalidade da inclusão das tecnologias em ambiente escolar/acadêmico, quando afirma que "[...] o mero acesso ao uso da internet, por meio de maior quantidade de computadores [...] não implica, por si só, a garantia de que o acesso aos conteúdos informativos se converta verdadeiramente em formação educacional."

Em síntese, não basta a previsão legal da instalação de computadores ou de internet de alta velocidade, se essa ação não for articulada com um planejamento amplo, sobre sentidos e

\footnotetext{
${ }^{2}$ Analisamos o texto da DCN que foi utilizado como referência quando da elaboração dos PPCs vigentes e analisados durante a realização do presente estudo.
} 
significados que incluam, além da instalação, o trabalho formativo dos sujeitos envolvidos ao ressaltar a importância e impacto dessas tecnologias em seus afazeres educacionais (processos de ensino e aprendizagem). Ainda assim, se a preocupação não for o contexto educacional, em particular a formação de professores e a melhoria das condições de trabalho, melhorias salariais, valorização da carreira profissional, será uma implantação "legalizada" para atendimento de poucos, ou seja, uma normalização das políticas para atendimento de uma hegemonia mercadológica, em vigor.

\section{ABORDAGEM DE PESQUISA E CONSTRUÇÃO DO CORPUS DE ANÁLISE}

Iniciamos a apresentação da trajetória de pesquisa indicando ao leitor/a que desenvolvemos uma pesquisa teórica com análise documental, por meio da qual, acessamos os Projetos Pedagógicos Curriculares de cinco Cursos de Graduação em Licenciatura, da Universidade Federal do Acre, Campus Rio Branco. A escolha dos Cursos foi orientada por um único critério de inclusão, qual seja: primeiro curso criado em cada um dos Centros Acadêmicos existentes na instituição e que ofertam Cursos de Graduação em Licenciatura.

Desta forma, após aplicar o critério de inclusão, passamos para os termos de busca iniciais: TIC ou TICs, Tecnologia da Informação e Comunicação e Tecnologia(s) no Projeto Pedagógico dos Cursos de Geografia ${ }^{3}$, Ciências Biológicas ${ }^{4}$, Matemática ${ }^{5}$, Pedagogia ${ }^{6}$ e Educação Física $^{7}$ (SILVA, THIESEN, 2021).

A análise do corpus empírico, por sua vez, esteve apoiada nas discussões teóricas de Michel Pêcheux (1975, 2006), e Eni Puccilnelli Orlandi (2003, 2009) sobre Análise do Discurso (AD), bem como de autores que abordam a Formação de Professores e o Uso de Tecnologias da Informação e da Comunicação em contexto educacional.

Importante destacar que, segundo Orlandi (2009) a AD trata da determinação histórica dos processos de significação e trabalha com os processos e as condições de produção da linguagem, onde há um deslocamento no tratamento do texto. Nesse sentido, com a AD "procurase compreender a língua fazendo sentido, enquanto trabalho simbólico, parte do trabalho social geral, constitutivo do homem e da sua história” (ORLANDI, 2003, p.15).

Nesse processo, o analista não se preocupa em responder o "quê", mas o "como", por isso, para Orlandi (2003) nessa abordagem não se trabalha o texto apenas como ilustração ou,

Como documento de algo que já está sabido em outro lugar e que o texto exemplifica, mas produz um conhecimento a partir do próprio texto, porque o

\footnotetext{
${ }^{3}$ Projeto Político Pedagógico Curricular aprovado pela Resolução CEPEX nº 06, de 25.04.2014.

${ }^{4}$ Projeto Político Pedagógico Curricular aprovado pela Resolução CEPEX no 27, de 14.10.2011.

${ }^{5}$ Projeto Político Pedagógico Curricular aprovado pela Resolução CEPEX n ${ }^{\circ}$ 36, de 22.11.2011.

${ }^{6}$ Projeto Político Pedagógico Curricular aprovado pela Resolução CONSU n ${ }^{\circ}$ 84, de 01.12.2009.

${ }^{7}$ Projeto Político Pedagógico Curricular aprovado pela Resolução CEPEX nº 02, de 27.04.2006.
} 
vê como tendo uma materialidade simbólica própria e significativa, como tendo uma espessura semântica: ela o concebe em sua discursividade (ORLANDI, 2003, p. 19).

Orlandi (2009) acrescenta que, considera o discurso, não como transmissão de informação, mas como efeito de sentidos entre interlocutores, enquanto parte do funcionamento social geral, onde os interlocutores, a situação, o contexto histórico social, e as condições de produção constituem o sentido da sequência verbal produzida.

Com base nos argumentos de Orlandi (2009), identificamos que prevalece a ideia de que, em um texto não existe somente um sentido, mas sentidos possíveis, pois a variação é inerente ao sentido dado pelo sujeito, uma vez que o contexto é constitutivo dele. Neste aspecto, a autora acrescenta que, abandona-se a ideia de um sentido nuclear, mais importante hierarquicamente, em relação a outros, pois todos os sentidos são, de direito, sentidos possíveis. Assim sendo, considerase que, em certas condições de produção, há de fato, dominância de um sentido, sem por isso, se perder a relação com outros sentidos possíveis.

\section{O CORPUS DE ANÁLISE E AS ANÁLISES POSSÍVEIS}

O corpus empírico e as análises que apresentamos emergem dos textos dos Projetos Pedagógicos de cada um dos cursos investigados. Para isso, levamos em consideração que uma palavra significa muito, porque ela tem textualidade, ou seja, quando a sua interpretação deriva de um discurso que a sustenta, que a provê de realidade significativa (ORLANDI, 2003).

Inicialmente destacamos o texto do PPC de Geografia estabelece como princípio básico para sua criação,

\footnotetext{
A preocupação com as relações sociais resultantes desse processo de constante transformação por que passa o espaço geográfico. Para a compreensão da dinâmica do espaço e de sua organização, o curso se empenha no uso de teorias e técnicas que permitam a formação de um profissional capaz de cumprir sua função como agente social, com eficiência e eficácia, independente de escala de análise que se deseja trabalhar (PROJETO PEDAGÓGICO DO CURSO DE GEOGRAFIA, 2013, p.18).
}

Percebemos, neste princípio, que as questões sociais citadas, incluem, de forma não explícita, as questões relacionadas às tecnologias e as implicações de seu uso. No entanto, essa interpretação não será comum a todos os professores, pois cada professor tem sua forma de interpretar o currículo de acordo com seus conhecimentos e suas crenças. Ou seja, a abordagem das novas tecnologias pode esbarrar, nesse caso, em preconceitos e práticas, que afastam a tecnologia e mantém uma formação em que predominam a reprodução de modelos ultrapassados.

Ainda em se tratando do Curso de Geografia percebemos que o currículo, além de disciplinas de conteúdo geográfico, também se concentra em

disciplinas de caráter instrumental, formação pedagógica essencialmente prática, capacitando dessa maneira, o futuro profissional para atender as novas 
exigências do mercado de trabalho e deverá também, cursar disciplinas e desenvolver atividades que proporcione ao Licenciado em Geografia atuar junto a setores de planejamento, pesquisas e participar de equipes interdisciplinares, fornecendo-lhe a instrumentação necessária para utilização de técnicas de representação gráfica de fenômenos de caráter geográfico. (PROJETO PEDAGÓGICO DO CURSO DE GEOGRAFIA, 2013, p.18).

O exposto nos remete a considerar que os conteúdos trabalhados devem capacitar o egresso para lidar com as exigências do mercado de trabalho, foco da formação deste profissional que cada vez mais, de diferentes formas, exige apropriação de conhecimentos sobre TICs, que ultrapassam o conhecimento do manuseio de dispositivos ou ferramentas tecnológicas e envolvem a percepção de tecnologias como promovedoras de grandes transformações sociais, econômicas e educacionais.

Dessa forma, os licenciados devem ter uma formação pautada na compreensão abrangente da relação existente entre ciência e tecnologia para que possam perceber que é possível transformar esses conhecimentos em práticas educativas e cotidianas mais eficientes. De acordo com Silveira e Bazzo (2005) a tecnologia e a ciência são meios necessários para garantir o desenvolvimento social e econômico.

Assim sendo, defendemos a conexão dos conteúdos curriculares abordados em sala de aula com a realidade dos alunos, de forma a possibilitar a apropriação de conhecimentos de forma mais significativa. No entanto, ao observarmos o currículo proposto no PPC de Geografia, encontramos apenas na ementa de uma disciplina optativa, denominada "Informática", com carga horária (60 horas), os conteúdos referentes às "tecnologias", vejamos: Estrutura geral do computador. Utilização de programas. Arquivo e dados. Sistemas Operacionais. Internet.

O PPC de Ciências Biológicas traça, por sua vez, nos seus objetivos específicos, a indicação de que curso propiciará ao licenciado "uma formação teórico-prática que estimule a elaboração do pensamento e a intervenção no processo ensino-aprendizagem, de forma crítica e criativa", de forma que o discente seja capaz de "desenvolver habilidades para a utilização de novas tecnologias e formas de comunicação" (Projeto Pedagógico do Curso de Ciências Biológicas, 2011, p. 5, 6). (Grifo nosso).

Para alcançar os objetivos citados, o curso de Ciências Biológicas apresenta os seguintes princípios:

[...] (ii) formação do professor licenciado em biologia com uma abordagem da aplicação dos conhecimentos científicos da área para o entendimento dos sistemas bióticos e abióticos e suas interações, na busca do bem-estar do ser humano e da sua relação harmoniosa com o meio ambiente; [...]. (iv) visão da ciência como um domínio dinâmico do conhecimento, oportunizando a incorporação de avanços científicos ocorridos na área da formação do professor; [...] (PROJETO PEDAGÓGICO DO CURSO DE BIOLOGIA, 2011, p. 7). 
Esses princípios nos remetem à preocupação do curso em incluir abordagens sobre conhecimentos científicos na área específica das Ciências Biológicas, além da preocupação em permitir a inclusão de conhecimentos relacionados aos avanços científicos na área de formação do professor, que, no nosso entendimento, está implícito as discussões sobre os avanços tecnológicos, que de forma direta ou indireta, contribuem para aprimorar a formação do professor na área das ciências biológicas.

Indica, dentre as competências elencadas, que o aluno deverá ser capaz de estabelecer relações entre ciência, tecnologia e sociedade. Esta previsão resulta da orientação elencada no Parecer CNE/CES 1.301 (2001, p.5) que aponta normas e diretrizes para composição dos currículos das licenciaturas. Além disso, ao licenciado em Ciência Biológicas, o PPC prevê que "consoante às Diretrizes Curriculares Nacionais para o curso de Ciências Biológicas assume-se o desenvolvimento das seguintes competências e habilidades":

[...] portar-se como educador, consciente de seu papel na formação de cidadãos, inclusive na perspectiva socioambiental [...] estabelecer relações entre ciência, tecnologia e sociedade [...] utilizar os conhecimentos das ciências biológicas para compreender e transformar o contexto sociopolítico e as relações nas quais está inserida a prática profissional, conhecendo a legislação pertinente. (CNE/CES 1.301, 2001, p. 2).

Percebemos, nas competências exigidas para o profissional na área de Biologia, uma preocupação em incluir componentes curriculares, que permita formar cidadãos capazes de compreender as dimensões socioambientais, as relações existentes entre ciência, tecnologia e sociedade e os contextos e as relações em que se inserem a prática educativa. Percebemos, portanto, nesse tópico, um cuidado em incluir as competências elencadas no texto das Diretrizes Curriculares Nacionais para os cursos de Biologia, da mesma maneira como está escrita na DCN, como forma de garantir o cumprimento da exigência da lei, que prevê, dentre outras, as seguintes competências:

d) Portar-se como educador, consciente de seu papel na formação de cidadãos, inclusive na perspectiva socioambiental;[...] g) Estabelecer relações entre ciência, tecnologia e sociedade;[...] i) Utilizar os conhecimentos das ciências biológicas para compreender e transformar o contexto sócio-político e as relações nas quais está inserida a prática profissional, conhecendo a legislação pertinente; j) desenvolver ações estratégicas capazes de ampliar e aperfeiçoar as formas de atuação profissional, preparando-se para a inserção no mercado de trabalho em contínua transformação; [...] e m) avaliar o impacto potencial ou real de novos conhecimentos/tecnologias/serviços e produtos resultantes da atividade profissional, considerando os aspectos éticos, sociais e epistemológicos (CNE/CES 1.301, 2001, p.4).

No entanto, ao observarmos as DCNs, identificamos que faltou no rol das competências do PPC do curso de Ciências Biológicas, previsões das seguintes abordagens:

j) desenvolver ações estratégicas capazes de ampliar e aperfeiçoar as formas de atuação profissional, preparando-se para a inserção no mercado de trabalho em contínua transformação; [...] e m) avaliar o impacto potencial ou real de 
novos conhecimentos/tecnologias/serviços e produtos resultantes da atividade profissional, considerando os aspectos éticos, sociais e epistemológicos (CNE/CES 1.301, 2001, p.4).

A ausência acima mencionada é, a nosso ver, preocupante, pois os estudantes dos cursos de licenciatura, em especial das Ciências Biológicas, precisam ser capazes de compreender que o mercado de trabalho sofre modificações e que, por este motivo, existe a necessidade de aperfeiçoamento para readequações causadas por essas modificações. Do mesmo modo, é necessário que este egresso compreenda o impacto de novos conhecimentos, tecnologias e serviços para sociedade, e em especial, para o mercado de trabalho e para a educação.

Ao observarmos o currículo proposto no PPC para o curso de Ciências Biológicas, constatamos na previsão dos tópicos de estudo indicações de abordagens sobre tecnologia, de forma explícita, somente na temática ambiente e saúde, conforme exemplificamos a seguir: “Ambiente e Saúde; [...] (ii) disciplinas optativas [...] - Tecnologia e Inspeção de Mel e Derivados, Tecnologia e Inspeção de Pescado e Derivados”.

Além dessa citação, encontramos, no tópico condições de implementação de proposta, as seguintes previsões:

(iii) Reforma e equipagem da sala ambiente do bloco Nely Catunda [...], Datashow, computador, [...]; (v) Construção e equipagem de um laboratório de informática com 50 computadores, [...] ligados em rede, para uso dos alunos e para a realização de aulas que exijam uso de programas de computador; (vi) Construção de um laboratório integrado de instrumentação para o ensino; (vii) Construção e equipagem de um auditório com 150 assentos, com protetor multimídia, tela de projeção, condicionador-de-ar com potência adequada ao volume do espaço, e mobília (PROJETO PEDAGÓGICO DO CURSO DE BIOLOGIA, 2011, p. 20).

Assim, é possível perceber que o sentido que emerge, do texto analisado, sobre tecnologias, nos fornecem indícios de que o curso, mesmo atendendo aos componentes previstos nas DCNs entende a contempla a tecnologia a partir da consideração dela como domínio instrumental de componentes tecnológicos como o computador, seus programas e a internet.

Em se tratando do curso de Educação Física, notamos que suas atividades serão, segundo o PPC, dimensionadas a partir dos seguintes objetivos:

i). Desenvolver nos estudantes de Educação Física, atitudes críticas democráticas acerca da sociedade, da Educação e da Educação Física Brasileira; ii) [...]; iii). Garantir ao aluno o acesso às tecnologias da informação e das comunicações, para que através da análise, da crítica e da contextualização, possa transformar às informações veiculadas massivamente, em conhecimento (PROJETO PEDAGÓGICO DO CURSO DE EDUCAÇÃO FÍSICA, 2005, p. 1).

Existe, de forma explícita, a preocupação em incluir elementos relacionados às TICs, como forma de cumprir o que está estabelecido nas Diretrizes Curriculares Nacionais, com o 
objetivo de possibilitar ao aluno uma visão mais ampliada sobre tecnologias, como ferramentas possíveis de transformar informações em conhecimento. O PPC prevê que o perfil do profissional, idealizado para o Curso de Licenciatura em Educação Física é de um profissional que,

[...]. Deve estar qualificado para analisar a realidade social, para nela intervir acadêmica e profissionalmente por meio das diferentes manifestações e expressões do movimento humano, visando à formação, a ampliação e o enriquecimento cultural das pessoas. O Licenciado em Educação Física deverá estar capacitado para o pleno exercício profissional no componente curricular Educação Física na Educação Básica (Educação Infantil, Ensino Fundamental e Ensino Médio) e profissional em suas exigências gerais, tais como inserção social da escola, domínio de teorias e processos pedagógicos (ensinoaprendizagem) e de teorias do desenvolvimento dos indivíduos em idade escolar. (PROJETO PEDAGÓGICO DO CURSO DE EDUCAÇÃO FÍSICA, 2005, p. 10).

Compreendemos que o profissional da Educação Física precisa ser capaz de analisar a realidade social da escola e estar capacitado para o pleno exercício profissional, em suas exigências gerais, tais como inserção social da escola, compreendendo que, deste contexto social, não se pode excluir as TICs, porque elas fazem parte da realidade de uma parcela de alunos e mesmo não sendo a de outros, é responsabilidade do/a professor/a de educação física lidar com essas diferenças dentro do contexto escolar, visibilizando as desigualdades sociais.

Para além disso, o PPC prevê que a formação profissional em Educação Física, assegure competência no exercício da docência e na incorporação dos conhecimentos básicos fundamentais que possibilitem ao professor "compreender o contexto sociocultural vigente e fazer-se nele agente de interação e transformação". (PROJETO PEDAGÓGICO DO CURSO DE EDUCAÇÃO FÍSICA, 2005, p. 7). Por este motivo, esta formação precisa ser conduzida "para o desenvolvimento de competências vinculadas à sua aplicação na realidade escolar, considerando as experiências anteriores e os conhecimentos adquiridos nos conteúdos das disciplinas" (PROJETO PEDAGÓGICO DO CURSO DE EDUCAÇÃO FÍSICA, 2005, p. 7). Para além disso, o curso de Educação Física deve priorizar uma formação para o desenvolvimento de competências, em sua composição, ao considerar que,

Todo acadêmico traz consigo experiências anteriores de diversas formas da cultura corporal do movimento. Estas experiências anteriores devem ser valorizadas no aprimoramento do conhecimento e no desenvolvimento das competências e habilidades do futuro profissional (PROJETO PEDAGÓGICO DO CURSO DE EDUCAÇÃO FÍSICA, 2005, p. 8).

Ao observamos a composição da estrutura curricular do curso de Educação Física, verificamos que não existem disciplinas específicas, que tratem, de forma explícita, as questões tecnológicas. Nesse sentido, foi necessário verificarmos as ementas das disciplinas para compreendermos como se dá a inserção dessa temática nos currículos, pois compreendemos que estas disciplinas podem ser contextualizadas com diferentes conteúdos sobre tecnologias, em 
diferentes contextos e aspectos, possibilitando ao aluno desenvolver competências e habilidades para lidar com TICs existentes, além de possibilitar uma visão menos simplista sobre as tecnologias e as possibilidades de seu uso. O PPC prevê também, que a formação em educação física será desenvolvida numa perspectiva disciplinar e interdisciplinar,

Com ênfase nos procedimentos de observação e reflexão, visando à atuação em situações contextualizadas, com o registro dessas observações realizadas e a resolução de situações-problema. A presença da prática profissional na formação do professor, que não prescinde da observação e ação direta, poderá ser enriquecida com tecnologias da informação, incluídos situações simuladoras e estudo de casos (PROJETO PEDAGÓGICO DO CURSO DE EDUCAÇÃO FÍSICA, 2005, p 16).

Verificamos que, mesmo não trazendo disciplinas específicas sobre tecnologias, o PPC do curso de licenciatura em Educação Física, prevê a inclusão de abordagens multidisciplinares, o que possibilita ao professor/a trabalhar temas que envolvem temáticas referentes ao contexto social, e nessas temáticas podem ser incluídas abordagens sobre tecnologias.

Percebemos também, em relação à infraestrutura do curso, que existe a previsão da criação de laboratórios de informática equipados com computadores e, além disso, a previsão de disponibilização de computadores para professores com acesso à internet, bem como de ampliação do laboratório de informática para os alunos (PROJETO PEDAGÓGICO DO CURSO DE EDUCAÇÃO FÍSICA, 2005, p. 38).

Nessa perspectiva, compreendemos que seja necessário despertar, não somente no aluno, mas no professor, na escola e na Universidade a conscientização de que a tecnologia é uma área de conhecimento ampla, que não envolve somente artefatos de informática, mas uma gama de conhecimentos que podem ser produzidos e utilizados, no nosso cotidiano, para benefício da sociedade. No entanto, para que este uso seja positivo e impacte de forma positiva a sociedade é necessário que os processos formativos promovam reflexões sobre suas potencialidades e fragilidades, em relação ao uso, ao distanciamento e acesso.

O PPC de Pedagogia, por sua vez, elenca como objetivos específicos, oportunizar situações que promovam no futuro professor competências para

dominar os conhecimentos específicos da docência multidisciplinar de forma
a possibilitar uma visão ampla e fundamentada do trabalho docente [...].
Indagar a ambiência escolar na sua complexidade e analisar sua prática
profissional, bem como as práticas escolares, admitindo-as como objetos de
reflexão e referência para a sua ação profissional [...] (PROJETO
PEDAGÓGICO DO CURSO DE PEDAGOGIA, 2009, p. 24).

Da mesma forma, indica que pensando em "uma alternativa de organização curricular que supere as visões polarizadas entre o macro e o microestrutural e entre a formação meramente teórica acadêmica e o praticismo" (PPROJETO PEDAGÓGICO DO CURSO DE PEDAGOGIA, 2009, p. 18), e, por isso, encontra-se pautado em princípios que privilegiam: 
i) o entendimento da educação como prática social, que tem por finalidade um processo de humanização que possibilite aos sujeitos a capacidade de usufruir o que a civilização produziu e produzir civilização. A direção e o sentido são a garantia de humanização (sentido crítico emancipatório); ii) a educação deve se constituir em objeto de estudo; iii) o processo pedagógico é algo que pode ser entendido de forma científica e o pedagogo, como profissional deve ter esse processo como objeto de estudo, investigação e intervenção; iv) o entendimento de que o profissional formado no curso de pedagogia deve conhecer o processo pedagógico na sua complexidade, entendendo a docência como um elemento desse processo (PROJETO PEDAGÓGICO DO CURSO DE PEDAGOGIA, 2009, p. 18).

Para além desses princípios, o PPC baseia-se na elaboração de uma organização curricular que leva em consideração o disposto no artigo 61 da LDBEN n. 9394/96, que trata da organização e da elevação do nível de formação dos professores da educação básica que tenham, dentre outros, os seguintes fundamentos: "I. a associação entre teorias e práticas, inclusive mediante a capacitação em serviço; II. Aproveitamento da formação e experiências anteriores em instituições de ensino e outras atividades" (BRASIL,1996, p. 30).

Nessa perspectiva, os diferentes componentes curriculares de ensino e aprendizagem previstos no PPC de pedagogia, estão organizados de acordo com os Núcleos Aglutinadores da Formação propostos pelas Diretrizes Curriculares Nacionais vejamos: "Núcleo de Estudos Básicos"; "Núcleo de Aprofundamento e Diversificação de Estudos"; "Núcleo de Estudos Integradores". Cada um dos núcleos apresenta três dimensões formativas: específica, complementar e eletiva. No núcleo de formação complementar "localizam-se aspectos que ampliam a formação docente, posto que privilegia discussões e experiências relacionadas à sociedade, a outros âmbitos de atuação do professor e a sua formação cultural mais geral" (PROJETO PEDAGÓGICO DO CURSO DE PEDAGOGIA, 2009, p. 30).

Quando da análise do PPC do Curso de Matemática, identificamos como principais elementos os que apresentaremos a seguir. Primeiramente destacaremos as competências, quais sejam:

Dos fundamentos que sustentam a escolha de conteúdos matemáticos a serem trabalhados e da metodologia pela qual tais conteúdos serão trabalhados, incluindo necessariamente o domínio dos instrumentos que permitem desenvolver o pretendido com eficácia.[...] Neste sentido, torna-se necessário que os nossos alunos e futuros professores desenvolvam conhecimentos sobre o contexto de trabalho, para que possa, ao escolher, ter condições para utilizálo com as várias possibilidades compreendendo até que ponto pode desviar as condições de sua sala de aula do tradicional, do esperado ou do determinado pela direção, pelas normas e pelas leis da instituição (PROJETO PEDAGÓGICO DO CURSO DE MATEMÁTICA, 2011 p. 5).

E ainda,

Uma sólida formação matemática, consolidando, aprofundando e ampliando os conceitos matemáticos já construídos, durante a formação na educação básica e levando os alunos a construir novos conhecimentos; A utilização e 
incorporação na atividade docente os recursos oferecidos pelas novas tecnologias [...] Qualificação profissional de professores que estejam cientes de sua responsabilidade social e adotem uma atitude, contínua, de análise crítica da realidade, para atuarem de forma mais eficiente menos excludente nos sistemas de ensino (PROJETO PEDAGÓGICO DO CURSO DE MATEMÁTICA, 2011 p. 7).

Para além das habilidades gerais, o profissional formado no curso de Licenciatura em Matemática deverá mobilizar as seguintes habilidades específicas:

Deve compreender, criticar e utilizar novas ideias e tecnologia para a resolução de problemas; deve estabelecer relações entre a Matemática e outras áreas do conhecimento; perceber a prática docente de Matemática como um processo dinâmico, carregado de incertezas e conflitos, um espaço de criação e reflexão, onde novos conhecimentos são gerados e modificados continuamente (PROJETO PEDAGÓGICO DO CURSO DE MATEMÁTICA, 2011, p. 1112).

Atendendo ao proposto pelo parecer CNE/CES 1.302/2001 que institui as Diretrizes Curriculares Nacionais para os cursos de Licenciaturas em Matemática, o currículo deve conter, dentre outros, os conteúdos, que trabalhem, de forma explícita, ou implícita, conteúdos sobre TICs, em diferentes perspectivas e acerca disso encontramos o seguinte

\begin{abstract}
Dos significados dos conceitos matemáticos, a fim de que ele possa contextualizá-los adequadamente. $\mathrm{O}$ mesmo pode-se dizer em relação aos processos escolares em geral: o aluno chega ao ensino superior com uma vivência e um conjunto de representações construídas ao longo da escolarização. É preciso que estes conhecimentos também sejam considerados durante o processo de formação (PROJETO PEDAGÓGICO DO CURSO DE MATEMÁTICA, 2011, p.13).
\end{abstract}

Além disso, baseado nesse conjunto de representações construídos, "o desenvolvimento do currículo será orientado por cinco eixos articulados entre si e demandados das habilidades e competências exigidos no presente projeto" (PROJETO PEDAGÓGICO DO CURSO DE MATEMÁTICA, 2011, p.13), conforme exposto a seguir: Conhecimento Específico; Dimensão Cultural e Política da Educação; Conhecimento do Trabalho Pedagógico; Cultura Geral e Profissional; Desenvolvimento e Processos Cognitivos. Além desses conhecimentos, as grandes áreas de conhecimentos que integram o currículo do curso de Licenciatura em Matemática proposto são as seguintes:

[...] Geometria [...] Também a contextualização histórica é essencial, bem como a garantia de que a intuição geométrica seja desenvolvida, além da capacidade de utilização de uma linguagem precisa. Informática Esta área vem se tornando cada vez mais presente no mundo contemporâneo. Ela adquire assim uma grande importância nos currículos. No caso de uma Licenciatura em Matemática deve-se apresentar programas computacionais que possam ser usados no ensino de Matemática na escola fundamental e média. Pode-se utilizar a área como fonte importante de apoio à aprendizagem de geometria e do cálculo. História e Filosofia da Prática de Ensino Essa área situa-se em uma dupla confluência: em que concepções influenciam a prática pedagógica; 
uma articulação entre os temas tratados nas áreas pedagógicas e os conteúdos matemáticos do restante do currículo da Licenciatura; o estabelecimento de pontes entre os conteúdos das diversas áreas do currículo da Licenciatura e aqueles que os licenciados irão lecionar em escolas do ensino básico; Formação Pedagógica Pensando o currículo [...] é fundamental inseri-lo no estudo sistemático das questões educacionais presentes na sociedade em que vive. Conceber e refletir sobre a teia de relações que constituem a escola, sobre a dinâmica social e as relações de poder que perpassam as instituições escolares e a vida coletiva é condição para que o futuro professor possa dominar as questões nucleares da realidade escolar, do significado sociopolítico do currículo e da profissão docente (PROJETO PEDAGÓGICO DO CURSO DE MATEMÁTICA, 2011, p. 15).

Existem ainda, na área de formação pedagógica, nove subáreas, essenciais para a formação do licenciado em matemática, expostos a seguir:

Educação e sociedade, Organização da Educação Básica e Legislação de Ensino, Fundamentos da Educação Especial, Psicologia da Educação, Organização Curricular e Gestão da Escola; Didática Aplicada, Prática de Ensino, Informática Aplicada ao Ensino de Matemática e Estágio Supervisionado (PROJETO PEDAGÓGICO DO CURSO DE MATEMÁTICA, 2011, p.18).

Como proposta de componente optativos, o PPC de matemática, apresenta um conjunto de disciplinas optativas, para que o aluno possa enriquecer

Seu currículo direcionando-o para a área que lhe for mais conveniente. Poderá aprofundar seus conhecimentos através da matemática pura ou aplicada, através da área de informática ou da educação, ou ainda poderá se aprofundar nos conhecimentos das ciências humanas através das disciplinas de História e Filosofia das Ciências, Filosofia, Cultura Brasileira e Culturas e Histórias Africanas dos Afrodescendentes e Indígenas no Brasil (PROJETO PEDAGÓGICO DO CURSO DE MATEMÁTICA, 2011, p. 23).

Dentre os recursos necessários ao funcionamento do curso de matemática, acrescenta-se ainda, que a previsão de

Criação de novas disciplinas, necessárias para compor o conjunto de atividades formativas do currículo proposto exigirá a contratação e ou a qualificação de pelo menos dois docentes na área de Educação Matemática. Exigirá também a contratação de técnicos qualificados para os laboratórios de Informática e Didática da Matemática, locais de reflexões, simulações de aulas e elaboração de materiais didáticos para a prática docente (PROJETO PEDAGÓGICO DO CURSO DE MATEMÁTICA, 2011, p. 28).

Além disso, dentre os recursos físicos e materiais necessários, ao funcionamento do curso, estão elencados, também: Ampliação e aquisição de equipamentos para o laboratório de informática; Aquisição software específicos para o Ensino da Matemática; [...] Aquisição de recursos Audiovisuais (PROJETO PEDAGÓGICO DO CURSO DE MATEMÁTICA, 2011, p. 28). 
A análise do corpus empírico, considerado no presente texto, exige que lembremos que, segundo Orlandi (2003), quando se diz algo, alguém o diz de algum lugar da sociedade para outro alguém, também, de algum lugar da sociedade e isso faz parte da significação. Assim sendo, o contexto e, as condições de produção são constitutivas do sentido, e a variação é inerente ao próprio conceito de sentido.

Na esteira do exposto, Orlandi (2009) destaca que,

Se pensarmos o contexto como constitutivo qualquer variação relativa às condições de produção é relevante para a significação. Daí podemos citar como mecanismos de efeito de sentidos desde o lugar social do locutor, ou o registro (enquanto estilo que aponta uma identidade social que tem função significativa) até relações menos diretas como é a da formação discursiva com a formação ideológica (ORLANDI, 2009, p. 161).

Analisando o cenário exposto é possível inferir que o sentido de tecnologias que emerge na maioria dos textos dos PPCs em questão, é limitado, pois os conteúdos propostos trabalham apenas com a parte lógica da informática, ou seja, programas, arquivos, dados e internet. Defendemos a tecnologia como campo de conhecimento que necessita de uma abordagem mais ampla, não podendo ser dissociada da compreensão da realidade tecnológica constitutiva da sociedade.

De outro lado, há elementos que apontam a preocupação dos cursos com a infraestrutura ratificando nosso entendimento, sobre a ideia de que o curso tem uma visão instrumentalista e tecnicista do uso destes dispositivos. O que consideramos preocupante, tendo em vista que, segundo Romaní (2012), a tecnologia tem um sentido muito mais amplo, o que indica a necessidade de repensar o sistema educacional para melhor preparar uma força de trabalho qualificada e adaptável, voltada para o uso consciente e crítico das tecnologias.

Por fim, destacamos que somente o PPC de Matemática possibilitou a utilização, a nosso ver, de um sentido mais amplo em relação aos conteúdos sobre tecnologias e as formas deles serem contemplados no currículo. Percebemos que existem disciplinas obrigatórias e optativas que tratam especificamente de temas relacionados às TICs, e que, em diferentes momentos, na elaboração da proposta do curso, fica evidente a preocupação da abordagem do tema.

Sendo assim, compreendemos que o discurso se constitui em seus sentidos, porque aquilo que o sujeito diz se inscreve em uma formação discursiva e não outra, para ter um sentido e não outro (ORLANDI 2003, p.43). Além disso, foi a análise do PPC de Matemática que nos ajudou a compreender o processo de produção de sentidos, a sua relação com a ideologia, e nos deu a possibilidade de estabelecer regularidades no funcionamento do discurso. Levando em consideração o que afirma Orlandi (2003) ao argumentar que todo discurso se relaciona com outros discursos, não existindo nesses discursos começo ou ponto final, visto que cada dizer se relaciona com outros dizeres, realizados, imaginados ou possíveis. 


\section{CONSIDERAÇÕES FINAIS}

Inicialmente queremos chamar a atenção do leitor para o fato de que, os PPCs dos cursos, quando de suas elaborações, devem contemplar as orientações trazidas pela LDB, e pelas demais normas que regulam o Sistema Nacional de Educação, como por exemplo Resoluções específicas de Formação de Professores, o Plano Nacional de Educação e as Diretrizes Curriculares Nacionais. Além disso, não podemos perder de vista que o licenciado precisa ser qualificado para o domínio e aprimoramento das abordagens científicas pertinentes ao processo de produção e aplicação do conhecimento, considerando as especificidades do contexto no qual se insere.

Nesse sentido, considera-se de fundamental importância que as tecnologias, e sua utilização, não sejam dissociadas da realidade social de docentes e discentes e, da mesma forma, que não se desconecte do conhecimento abordado em âmbito acadêmico/escolar e este, por sua vez, não se desconecte da realidade na qual o aluno está inserido e, da mesma forma, da realidade na qual será inserido profissionalmente.

Por isso, registra-se que alguns dos PPCs analisados não contemplam a legislação vigente e, da mesma forma, fundamentam-se em termos e discussões teóricas acerca dos processos formativos e de ensino e aprendizagem breves e frágeis. Dito isso, a análise do corpus empírico e a identificação dos principais sentidos que emergem destes textos, acerca das "Tecnologias" e suas implicações para a formação de professores, nos permitem considerar, especialmente, o que segue:

De um lado, para a expressão tecnologias os textos dos PPCs, permitem evidenciar os seguintes sentidos: (i) as consideram como meras ferramentas e dispositivos tecnológicos digitais; especificamente computadores e celulares; (ii) as têm como sinônimo de evolução; (iii) as percebem como responsáveis por benefícios e avanços e (iv) as indicam como ferramentas que facilitam a vida das pessoas.

De outro lado, em termos das implicações para a formação de professores, os sentidos que emergem nos permitiram considerar que a abordagem, dada ao termo, pelos textos dos PPCs, é limitada, pois não a insere em seus currículos como um campo próprio de saberes e por isso (i) não preveem a abordagem, em seu currículo, de disciplinas que abordam as tecnologias e suas implicações na ciência e na sociedade; (ii) não consideram que as tecnologias possam ser incluídas como recursos e temas capazes de serem trabalhados de forma contextualizada e interdisciplinar com as demais disciplinas e (iii) não vislumbram a utilização das tecnologias como aparato que pode desempenhar um papel importante na melhoria dos processos de ensino e de aprendizagem.

Tais percepções se veem ratificadas pelos achados de outra pesquisa desenvolvida no estado no Acre e que indica o seguinte: 
o uso das TICs, pela simples utilização, não se justifica, pois defendemos que a escolha de um recurso, ou de uma metodologia, ou ainda, de uma ferramenta, deve ser realizada a posteriori, e não a priori, pois as práticas pedagógicas devem se caracterizar como ações intencionais que atendem a objetivos específicos. (NASCIMENTO, ARAÚJO, SILVA, NICOLLI, 2021, p. 17).

Assim, o que se percebemos é que, de um lado, tais sentidos nos permitem considerar que a abordagem, dada ao termo TICs pelos textos dos PPCs, é limitada, pois não a insere em seus currículos como um campo próprio de saberes, resultando em um tratamento simplista e, ao mesmo tempo, de certa forma, salvacionista e, de outro, existe, nos textos analisados, uma série de ausências, que segundo Orlandi (2003) resultam em descontinuidade, dispersão, incompletude, falta, equívoco, contradição, constitutivas tanto do sujeito como do sentido. Essas ausências e incompletudes significam, para a autora supracitada, movimento silenciamentos. Desse modo, o silêncio é trazido à discussão para permitir a reflexão sobre a linguagem e a possibilidade de atribuição de sentidos, porque segundo a autora, quanto mais falta, mais possibilidade existem de atribuição e sentido.

\section{REFERÊNCIAS}

BRASIL. Lei no . 9.394, de 20 de dezembro de 1996. Lei de Diretrizes e Bases da Educação Nacional. Brasília, DF: 20 de dezembro de 1996. Disponível em: http://www.planalto.gov.br/ccivil_03/Leis/L9394.htm.

BRASIL. Lei no 13.005, de 25 de junho de 2014. Aprova o Plano Nacional de Educação. Disponível em: http://www.planalto.gov.br/ccivil_03/_Ato2011-2014/2014/Lei/L13005.htm.

BRASIL. Resolução CNE/CP n ${ }^{0}$, de 18 de dezembro de 2018. Institui Diretrizes

Curriculares Nacionais para o Curso de Graduação em Educação Física. Disponível em: http://portal.mec.gov.br/index.php?option=com_docman\&view=download\&alias=104241rces006-18\&category_slug=dezembro-2018-pdf\&Itemid=30192.

BRASIL. Resolução CNE/CP n' 14, de 13 de março de 2002. Institui Diretrizes Curriculares Nacionais para o Curso de Graduação em Geografia. Disponível em: http://portal.mec.gov.br/cne/arquivos/pdf/CES142002.pdf.

BRASIL. Resolução CNE/CP no 7, de 11 de março de 2002. Institui Diretrizes Curriculares Nacionais para o Curso de Graduação em Ciências Biológicas. Disponível em: http://portal.mec.gov.br/cne/arquivos/pdf/CES07-2002.pdf.

BRASIL. Resolução CNE/CP no 3, de 18 de fevereiro de 2003. Institui Diretrizes Curriculares Nacionais para o Curso de Graduação em Matemática. Disponível em: http://portal.mec.gov.br/cne/arquivos/pdf/ces032003.pdf.

BRASIL. Resolução CNE/CP n ${ }^{0}$, de 19 de fevereiro de 2002. Institui a duração e a carga horária dos cursos de licenciatura, de graduação plena, de formação de professores da Educação Básica em nível superior. Disponível em: http://portal.mec.gov.br/cne/arquivos/pdf/CP022002.pdf.

LAZZARATO, M. O governo do homem endividado. São Paulo: N-I edições, 2017. 
NASCIMENTO, B. C. do, ARAÚJO, R. D., SILVA, F. S. O. da, \& NICOLLI, A. A. Tecnologias da informação e comunicação como ferramenta pedagógica no ensino superior. Linhas Críticas, 27, e39110, 2021. https://doi.org/10.26512/lc27202139110

ORLANDI, E. P. Análise de discurso: princípios e procedimentos. 8. ed. Campinas: Pontes, 2003.

ORLANDI, E. P. As formas do silêncio no movimento dos sentidos. 6. ed. Campinas: Unicamp, 2009.

ROMANI, C. C. Explorando tendencias de educação para o século XXI. Cadernos de pesquisa, v. 42, n. 147, p. 848-867, set - dez, 2012. Disponível em:

https://www.scielo.br/pdf/cp/v42n147/11.pdf.

SEVERINO, A. J. Metodologia do trabalho científico. 23. ed. são Paulo: Cortez, 2007.

SILVA, A. C. da; THIESEN, J. da S. Estado do conhecimento: caminhos que fundamentam a pesquisa na formação inicial de professores/as. In: Anais das Reuniões Regionais da ANPED - $3^{\text {a }}$ Reunião Científica da ANPEd-Norte, Tocantins: 2021. Disponível em: http://anais.anped.org.br/regionais/sites/default/files/trabalhos/21/7077texto_proposta_completo.pdf.

ZUIN, A. A. S. O plano nacional de educação e as tecnologias da informação e comunicação. Educação e sociedade, Campinas, v. 31, n. 112, 2010. Disponível em: http://www.scielo.br/scielo.php?script=sci_arttext\&pid=S010173302010000300016\&lng=pt\&n $\mathrm{r}=$ iso.

Recebido em: 15/01/2022

Aprovado em: 05/02/2022 